\title{
Magazine of
}
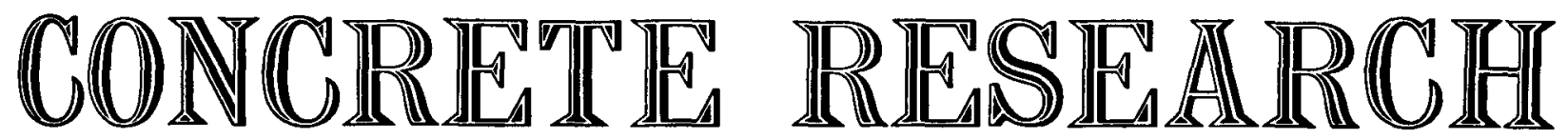

Volume 12, Number 34: March 1960

\section{EDITORIAL ADVISORY BOARD}

A. L. L. Baker, D.Sc.(Eng.), M.I.C.E., M.I.Struct.E.

Professor of Concrete Technology, University of London, Imperial College of Science and Technology

W. Fisher Cassie, Ph.D., M.S., F.R.S.E., M.I.C.E., M.I.Struct.E.

Professor of Civil Engineering, University of Durham, King's College, Newcastle upon Tyne

R. H. Evans, C.B.E., D.Sc., D.ès Sc., Ph.D., M.I.C.E., M.I.Mech.E., M.I.Struct.E.

Professor of Civil Engineering, University of Leeds

T. W. Parker, M.Sc., Ph.D., F.R.I.C.

Deputy Director of Building Research, Department of Scientific and Industrial Research

A. D. Ross, B.Sc., Ph.D., F.R.S.E., M.I.C.E.

Professor of Civil Engineering, University of London, King's College

SECRETARY TO THE BOARD AND EDITOR

Ralph P. Andrew, M.A., Ph.D.

Published by the Cement and Concrete Association, 52 Grosvenor Gardens, London, SWI : Belgravia 6661 


\section{Editorial comment}

ONLY TOO RARELY are those responsible for the production of a journal consulted by authors before their papers have been submitted for consideration, although with very little extra trouble in the preparatory stage an author could save both himself and the editorial staff much unnecessary work, and facilitate the putting of his paper into print-and, indeed, improve the chances of his paper ever appearing in print. It is perhaps appropriate, therefore, to state here a few of the more important points that an author should bear in mind when preparing a paper for publication.

Most important of all, of course, is to decide whether or not the paper is worth writing anyway, and if it is, what journal it would be suitable for. Much disappointment would be avoided if authors gave far more thought to these questions. We must assume here, however, that the author is convinced he has something to say, and that this Magazine is the appropriate place. The author must now convince the Editorial Advisory Board that this is so, and the easier the paper is to read the more favourably they will look upon it. A neatly typed paper, written in simple clear English, will create a good first impression and is worth going to some trouble to achieve.

Still of a high order of priority is the necessity for the manuscript to be exactly what the author wishes to be printed: the submission of proofs to an author is intended merely to allow him to ensure that his manuscript has been faithfully reproduced, and is not intended to give him the opportunity of revising his paper. The cost of making alterations once the type has been set is quite high, and corrections on the proof should really be corrections and not second thoughts.

Papers should be typed, on one side of the paper only, double-spaced and with ample margins; the size of sheet-within reasonable limits-is not important. Alterations, as long as they are legible, may be made by hand on the typewritten manuscript, although any page bearing a large number of alterations should be re-typed. The relative importance of the various headings should also be made clear.

The submission of papers to the Editorial Advisory Board is greatly accelerated if authors can send six copies of their paper in the first place, although it is appreciated that this may not always be possible. In any case one copy should be a top copy; it is only fair to the compositor to give him the clearest copy possible, particularly when it is full of mathematical expressions or technical terms with which he will not be familiar. Mathematical expressions, and in particular Greek letters used as symbols which are not available on the average typewriter, are best inserted by hand, and particular care should be taken to ensure that these are correct on the manuscript; the printer has to set mathematical workings by hand, and it must be particularly galling to the compositor who has set a complicated piece of work to see it come back for alteration.

Illustrations may be in the form of line diagrams or photographs. The former should preferably be ink tracings from which all lettering has been omitted, this being shown on a separate print. (For reproduction, the lettering will be set in type of an appropriate size.) The tracings should be approximately two or three times the size to which they are likely to be reproduced, and the amount of lettering on the diagrams should be kept to a minimum. Photographs should be glossy and of good contrast, preferably halfplate size. And please do make sure that all the illustrations are referred to in the text, so that the printer will know where they should appear.

Tables should be typed on separate sheets, with all the columns clearly labelled; they too should all be referred to in the text. Only in exceptional circumstances should tabular matter repeat information given in graphical form.

Unfortunately there is as yet no standard system covering all the symbols authors are likely to require in their papers, although there is universal acceptance of some of the symbols, such as $E$ for the modulus of elasticity and $g$ for the gravitational acceleration. As a result, two papers in the same issue of this Magazine are quite likely to use quite different systems of notation, and the reader who wishes to compare the results of two different authors has life made more complicated by the different notations adopted. A committee of the British Standards Institution is working on this problem, however, and it is hoped that recommendations for symbols will be published in the fairly near future. Until then, all that we can ask is that authors use a notation which is as simple as possible, which does not use the same symbol for more than one purpose, and which really is required.

Every journal has its own "House Style", i.e. its system of abbreviations for units (p.s.i., lb/in', lb. per sq.in., etc.) and its preference for spelling (connection, connexion, etc.), and for those interested, this Magazine follows B.S. 1991 for units and the Oxford Dictionary for spelling. Authors need not worry unduly on this score, although naturally if these styles are adopted in the manuscript it will save alteration in the editorial office. If, however, all authors would submit clearly typed manuscripts, saying as briefly as possible what they really do want to say, the editor's task would be a much easier one. 